\title{
Vaginal Birth after One Caesarean Section-Ten Years Experience in a South Eastern Nigerian Hospital
}

\author{
O. U. Chidi Esike ${ }^{*}$, C. Robinson Onoh ${ }^{1}$, B. Okechukwu Anozie1, U. J. Odidika Umeora ${ }^{1}$, \\ 0. Christian Aluka², E. Deirdre Twomey ${ }^{3}$ \\ ${ }^{1}$ Department of Obstetrics and Gynaecology, Federal Teaching Hospital, Abakaliki, Nigeria \\ ${ }^{2}$ Department of Obstetrics and Gynaecology, Abia State Univerity Teaching Hospital, Aba, Nigeria \\ ${ }^{3}$ Mile Four Hospital, Abakaliki, Nigeria \\ Email: *drchidiesike@yahoo.com
}

Received 8 February 2016; accepted 17 March 2016; published 21 March 2016

Copyright (C) 2016 by authors and Scientific Research Publishing Inc.

This work is licensed under the Creative Commons Attribution International License (CC BY). http://creativecommons.org/licenses/by/4.0/

(c) (i) Open Access

\begin{abstract}
Background: The rising caesarean section rate worldwide is an increasing source of concern to all. A significant contributor to this is a previous caesarean delivery. One strategy in the armamentarium of obstetricians for reducing this is vaginal birth after one caesarean section (VBAC). The safety, outcome and complications of this procedure in our Center which is in a developing country had never been studied hence the need for this work. Aim: To find out the outcome and complications of vaginal births after one caesarean delivery in our Center. Method: A retrospective study involving a ten-year review of all cases of trials of labour after one caesarean delivery in our Center was done. Result: Of the $\mathbf{3 0 5}$ trials of labour after one caesarean delivery, 221 women had vaginal birth giving a vaginal birth after one caesarean section rate of $72.5 \%$. Majority of the babies $303(99.2 \%)$ were alive and had good Apgar scores while $2(0.7 \%)$ died giving a perinatal mortality rate of 7 per 1000 babies. There were complications in $21(6.7 \%)$ of the women with retained placenta, in $7(2.3 \%)$ of the women as the commonest, followed by postpartum haemorrhage in $6(1.96 \%)$. Five $(1.62 \%)$ women had scar dehiscence while $3(0.98 \%)$ had uterine rupture. Conclusion: Vaginal birth after one caesarean section is safe in well selected cases even in our resource poor settings. It offers our women a culturally-acceptable option of fulfilling long-held dreams of vaginal delivery even after one caesarean section and should be offered to our women whenever possible.
\end{abstract}

\section{Keywords}

One Previous Caesarean Section, Vaginal Birth, Southeast Nigeria

\footnotetext{
${ }^{*}$ Corresponding author.
} 


\section{Introduction}

Caesarean section is one of the most common surgeries in the world. Though it can save lives and is necessary when vaginal delivery might pose a risk to the mother and baby, it can cause significant complications, disabilities or even death especially in settings that lack the facilities to conduct safe surgeries or treat potential complications. Caesarean section should therefore be performed only when medically necessary [1]. Over the years, there has been a steady rise in the rates of caesarean sections all over the world [2] [3]. As a result of these increasing caesarean deliveries, there has been increasing number of pregnancies after caesarean delivery. These pregnancies potentially expose the women to the risks of a previous caesarean delivery like uterine rupture, haemorrhage, placenta preaviae, anaesthetic problems, etc. [4].

The increase in the rate of caesarean delivery was inter alia, attributable to Cragin's dictum of “once a caesarean always a caesarean” [5]. Caesarean section, however, is associated with increased morbidity and mortality when compared to vaginal delivery especially in resource poor countries [1]. Perhaps in recognition of the dangers posed to the mother and fetus by caesarean delivery [6] [7], various measures have been employed to reduce the caesarean section rates. One of such measures is the trial of labour after one previous caesarean delivery [1] [8]. In fact, there is consensus by the National Institute of Health and Excellence, Royal College of Obstetricians and Gynaecologists, American College of Obstetricians and Gynaecologists and National Institute of Health that planned vaginal delivery after one Caesarean section is a clinically safe option for majority of women with a single previous lower segment caesarean section [9]. In making the above assertion, they went on further to state that such a strategy is not just supported by health economic modeling but also would at least limit any escalation of caesarean delivery rate and maternal morbidity associated with multiple caesarean deliveries. In addition to these numerous benefits, this option of delivery provides our women who desire a vaginal delivery after a previous caesarean delivery with the possibility of achieving the long-cherished goal of a vaginal birth even after one caesarean delivery.

Though the importance attached to vaginal delivery may seem trivial to people and practitioners in advanced climes, it is indeed a very serious consideration to our women in developing countries where abdominal delivery is often regarded as a denial of normal motherhood - a view that puts pressure on women to attempt vaginal delivery after previous caesarean section often without proper supervision.

The outcome, safety and associated complications of vaginal birth after one caesarean section differ from region to region and even in different parts of the same country. It is against this background that we are undertaking this study to find out the outcome of our management of vaginal births after one caesarean section and the associated complications and to compare these with those of other workers. We consider this work even more compelling because it had not been done before in our Centre, Mater Misericordiae Hospital, Afikpo.

\section{Materials and Methods}

This is a retrospective descriptive study carried out at Mater Misericordiae Hospital Afikpo, Ebonyi State of Nigeria. After ethical approval was obtained for the study, a search was made through the labour ward delivery and theater registers for all the deliveries conducted from June 2002 to June 2011. From these, all the cases of trial of labour after one caesarean section were got. Their case notes were retrieved and all the relevant information was extracted and analyzed. Of the 318 case notes retrieved, only the information in 305\% or 95.9\% was complete and used for the study. The information retrieved included demographic data of the mothers, labour events and outcome, sex and Apgar scores of babies and any complications associated with labour and peurperium.

Those included in this study were parturient that had had one previous caesarean delivery for a non- recurrent indication whose surgery was done by skilled personal in a trusted health institution and the surgical wound healed by primary intention. These parturient in the index pregnancy haboured a singleton, average-sized fetus, had adequate pelvis with no maternal or fetal complications. The exclusion criteria were parturient who had one previous caesarean section for a recurrent indication, had wound breakdown or any other condition during the previous caesarean section that could have been thought to affect the integrity of the scar on the uterus who in the present pregnancy has inadequate pelvis, macrosomic fetus or a fetus with abnormal lie or presentation or had any condition that would contra-indicate a vaginal delivery.

In this study, a booked patient is a pregnant woman who came to the hospital to register into the antenatal clinic so that her pregnancy can be looked after in the hospital. In this study also, vaginal birth after caesarean 
section rate is the percentage of women who had one previous caesarean section and had trial of labour and succeeded in having vaginal birth over all the women with one previous caesarean section who had trial of labour over the study period multiplied by 100 .

Mater Misericordial hospital, Afikpo where this work was done is a Roman Catholic secondary/referral Mission hospital in Afikpo North Local Government Area of Ebonyi State, one of the 36 states that make up Nigeria. It is located in the South East Geopolitical zone of Nigeria. The Hospital was founded in 1948 by the Medical Missionaries of Mary congregation the Roman Catholic Church. It has a school of Nursing, a school of Midwifery and is accredited by the National Medical Post graduate College of Nigeria, the West African College of Surgeons and the Royal College of Obstetricians and Gynaeccologists England for training of resident doctors in Obstetrics and Gynaecology. It is also a training center for residents in General Medicine. The hospital offers secondary and referral health services and full gynaecological and obstetric services to her immediate environ, Afikpo, Ebonyi state and the surrounding Cross River, Abia, Imo and Enugu States. Afikpo where the hospital is situated is the second largest town in Ebonyi state after the state capital, Abakaliki. The hospital has 150 obstetric beds with an average annual delivery of about 1114 .

\section{Results}

During the period under review, there were 11,139 deliveries out of which 305 women or 2.7 percent of the women were selected for vaginal delivery after one caesarean section. Of this number, 221 parturient out of the 305 that had trial of labour after one caesarean delivery succeeded in delivering vaginally. This gives a vaginal birth after one caesarean section rate of $72.5 \%$.

Majority of the patients in our study as shown in Table 1, 120 (42.3\%) were in the 26 to 30 years age bracket followed by 73 (23.9\%) in the 31 to 35 years bracket. 288 (94.4\%) were booked. Majority, 205 (67.2\%) were in the para 2 - 4 bracket while $38 \%$ or $12.5 \%$ were primiparas. Majority, 189 (62\%) delivered at term and majority also, $221(72.4 \%)$ as shown in Table 2 delivered by spontaneous vaginal delivery. 84 parturient (27.6\%) delivered by emergency lower segment caesarean section. Ten out of this number were from the unbooked group.

Table 1. Socio demographic characteristics.

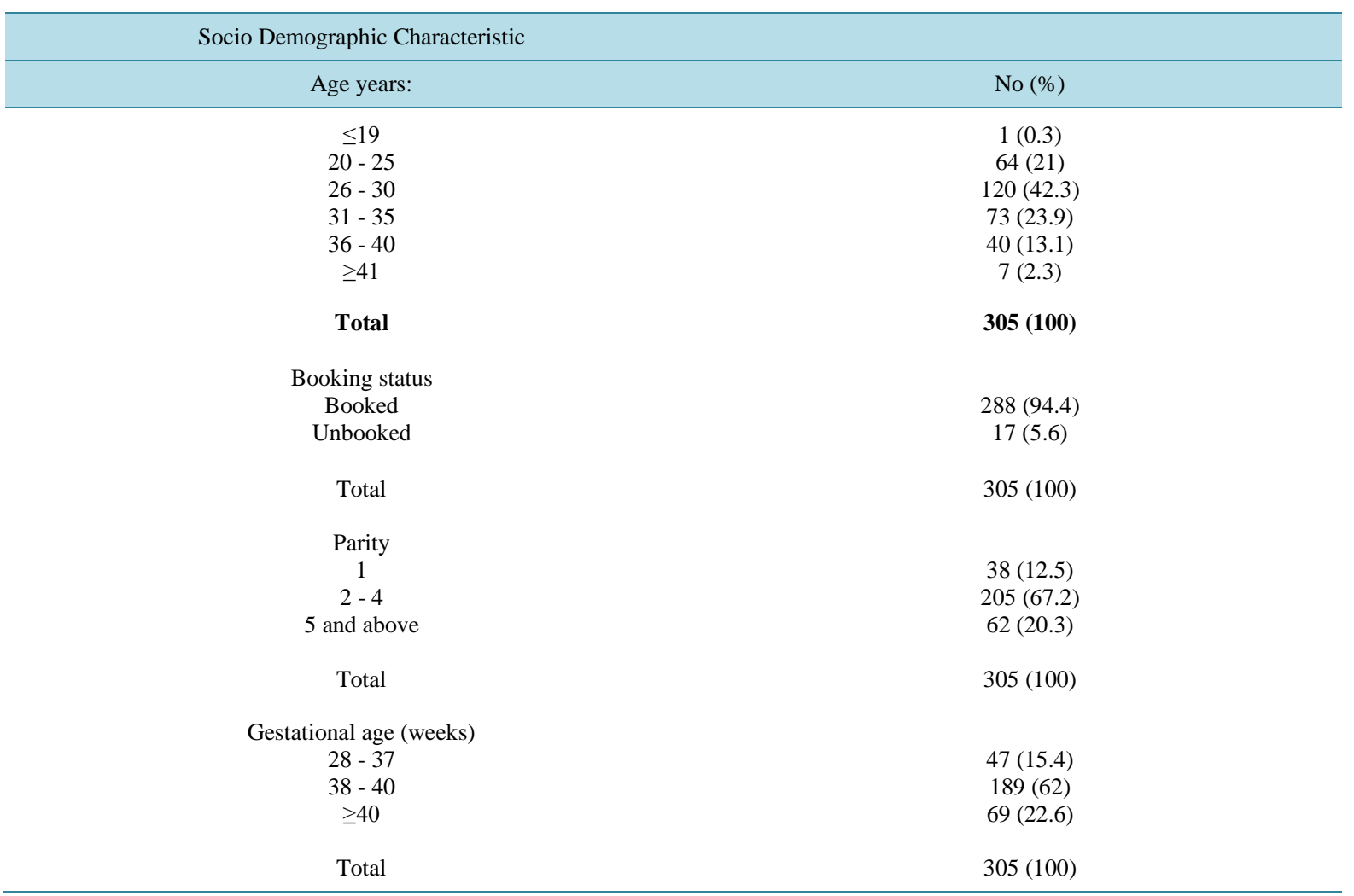


As shown in Table 3, of the 305 babies delivered, 303 were alive. Majority of them, 240 (79.2\%) had apgar scores of 8 - 10, 48 (15.8\%) apgar scores of 5 to 7 and 16 (5.6\%) apgar scores of 1 - 4 in the first minute. Two babies died giving a perinatal mortality rate of 7 (seven) babies per 1000 deliveries (Table 3). There was no maternal death.

Complications occurred in 21 (6.9\%) of these parturient as shown in Table 4. Seven (2.3\%) of these women had retained placenta, 6 (1.96\%) postpartum haemorrhage, 5 (1.62\%) uterine dehiscence and $3(8 \%)$ uterine rupture.

\section{Discussion}

In our Center, vaginal birth after one caesarean section was achieved by 221 of the 305 parturient that had trial of labour after one caesarean delivery. This gives a vaginal birth after one caesarean section rate of $72.5 \%$. This $72.5 \%$ success rate is high and could have been higher if all our patients were selected by us. This is because ten (58.8\%) of the 17 unbooked patients (Table 1 ) who came were already in labour and had to be managed and they were delivered by caesarean section. Some of these patients decided to keep away from the hospital for fear of caesarean section and only came when complication had developed and had to be sectioned.

The high rate recorded in our center could be due to good patient selection and painstaking monitoring of the patients in labour with partograph. Our success rate is in consonance with some other studies from other Centers where rate was quoted to range from 50 to 85 percent [4] [10]-[13]. Some of these Centers are in the more developed countries. We have similar rates to them, this could be due to the afore-mentioned close monitoring of

Table 2. Method of delivery.

\begin{tabular}{|c|c|c|c|}
\hline Method & Booked & Unbooked & Total \\
\hline \multirow{3}{*}{$\begin{array}{c}\text { Vaginal delivery } \\
\text { Emergency caesarean section }\end{array}$} & $214(70.2)$ & $7(2.2)$ & $221(72.4)$ \\
\hline & 74 (24.3) & $10(3.3)$ & $84(27.6)$ \\
\hline & & & 305 (100) \\
\hline
\end{tabular}

Table 3. Characteristics of babies.

\begin{tabular}{cc}
\hline Characteristics & No (\%) \\
\hline State of babies on delivery & $303(99.3)$ \\
Alive & 2 \\
Dead & $(0.7)$ \\
perinatal mortality rate & $305(100)$ \\
Total & \\
Sex & $172(56.6)$ \\
Male & $133(43.6)$ \\
Female & $305(100)$ \\
Total & \\
Apgar scores & \\
$8-10$ & $240(79.2 \%)$ \\
$5-7$ & $48(15.8)$ \\
$1-4$ & $15(5.6)$ \\
Total & $303(100)$ \\
\hline
\end{tabular}

Table 4. Complications of vaginal birth after caesarean section.

\begin{tabular}{ccccc}
\hline Type of complication & Retained Placenta & $\begin{array}{c}\text { Postpartum } \\
\text { haemorrhage }\end{array}$ & Uterine rupture & Scar dehiscence \\
\hline No (\%) & $7(2.3)$ & $6(1.96)$ & $3(0.98)$ & $5(1.62)$ \\
\hline
\end{tabular}


our patients with partograph. Also because of fear of litigation in their practice environment [10] they were more likely to have a low thresh hold to caesarean sections thereby reducing their rates. The system of their monitoring of their patients with continuous electronic monitoring devices had been noted to increase caesarean section rates [14]. Our success rate of vaginal birth after one caesarean section rate of $72.5 \%$ also falls within the range of $60 \%$ to $80 \%$ which ACOG and SOQC guideline got from analysis of various studies in their series. This may be due to our protocol for vaginal birth after caesarean section being in tandem with the standard protocol for conducting VBAC world over.

Our rate of vaginal birth after one caesarean section of $72.5 \%$ is greater than the $59.5 \%$ recorded by Obiechena et al. [15] at Nnewi, Nigeria. This may be as a result of their having a lower threshold of recourse to caesarean section in their Center.

Though majority of our patients were booked, the 17 (5.6\%) unbooked patients though small contributed significantly to the outcome of VBAC in our centre. This is because $10 \%$ or $58.8 \%$ of these unbooked patients delivered by caesarean section (Table 2) thereby significantly impacting negatively on the success rate of our Center in VBAC. Of the 305 deliveries, 172 (56.6\%) males and 133 (43.8\%) females, 302 (99.3\%) were delivered alive and two were dead giving a perinatal mortality rate of 7 per 1000 births (Table 3). This perinatal mortality rate is less than the 19.7/1000 recorded at Nnewi [15]. This might be due to the fact that in very big health institutions in the third world countries, beaurocracy can be an impediment to fast delivery during emergencies like fetal distress from uterine rupture or any such complication of vaginal birth after a caesarean delivery.

That 74 (24.3\%) of our patients were delivered by emergency lower segment caesarean section agrees with the assertion of Sharma and Throp-Beeston [16] that 20\% to $40 \%$ of attempts at trial of labour following a prior caesarean section will fail. Omigbodun also noted that the commonest complication of an attempt at vaginal birth after caesarean section was failure to achieve vaginal delivery thereby necessitating a caesarean section [4]. Our rate is lower than the $40.5 \%$ caesarean section rate got in Nnewi [15]. This may be because they have a lower thresh hold to caesarean section and/or due to their use of electronic fetal monitoring.

Fifteen or $5.6 \%$ of these babies delivered per vaginam after one caesarean section in our Center suffered from severe asphyxia as they had apgar scores ranging from 1 to 4 . This is not good enough as these babies may suffer life-long disabilities that will detract from their quality of life. It is recommended that all efforts must be made by us in future to reduce this drastically in our future management. This number of asphyxiated babies could be because we monitored our parturient only by intermittent auscultation of the fetal heart using Pinard stethoscope which may not have been sensitive enough for us to pick up some cases of fetal distress early enough for intervention.

Twenty-one (6.9\%) of the women on our center had various complications as shown in Table 4 . The commonest complication was retained placenta in 7 or $2.3 \%$ of this number. The high rate of this complication is in keeping with a scar on the uterus being a risk factor for its occurrence especially in anteriorly located placenta [4]. Six (1.96\%) of our patients had postpartum haemorrhage. Three of our parturient or $0.98 \%$ had uterine rupture while $5(1.62 \%)$ had scar dehiscence. Though the reported rate of uterine rupture varies in different studies, our rate of uterine rupture of $0.98 \%$ is within the quoted rate of $0.2 \%-1.5 \%$ for lower transverse uterine incisions [4]. Our rate of $0.98 \%$ is about the same rate of $0.7 \%$ recorded at Nnewi but our uterine dehiscence rate of $1.62 \%$ is less than the $3.9 \%$ in their series. Our rates of uterine rupture being the same may be because our practice environment is the same while having higher rate of uterine dehiscence may be due to the aforementioned beaurocratic bottle necks in big health institutions in getting the different members of the health team to work seamlessly in an emergency such as an impending rupture or dehiscence when trying of labour in women with one previous caesarean section. $1.96 \%$ of our parturient had postpartum haemorrhage complicating their delivery. This is less than the $2.6 \%$ complication of postpartum haemorrhage recorded in Nnewi. The reason for this difference is as aforementioned.

From this study which is a retrospective descriptive study and has all the limitations of this type of study, vaginal birth after one previous caesarean section is possible in well selected cases in resource poor settings. Whenever possible, our women should always be availed of this safer and relatively less expensive option (when compared to caesarean section) of still fulfilling their cherished and long-held dream of achieving the more natural vaginal delivery after they have had one caesarean section.

\section{References}

[1] (2015) World Health Organisation News, Release 10 April 2015. Media Center, Genva. 
[2] (2010) Vaginal Birth after Previous Caesarean Delivery. ACOG Practice Bulletin Number 115, Clinical Management Guidelines for Obstetrician-Gynecologists.

[3] Okonta, P.I., Otoide, V.O. and Okogbenin, S.A. (2003) Caesarean Section at the University of Benin Teaching Hospital Revisited. Tropical Journal of Obstetrics and Gynaecology, 20, 63-66.

[4] Omigbodum, A.O. (2002) Vaginal Birth after Caesarean Section. In: Emuveyan, E.E. and Kwawukume E.Y., Eds., Comprehensive Obstetrics in the Tropics, Asante and Hittscher, Dansoman, 22-128.

[5] Cragin, E.B. (1916) Conservatism in Obstetrics? New York Medical Journal, 104, 1-3.

[6] Incerpi, M.H. (2013) Operative Delivery. In: Decherney, A., Nathan, L., Laufer, N. and Roman, A.S., Eds., Current Diagnosis and Treatment, Obstetrics and Gynaeology, 11th Edition, Mcgraw Hill Medical, New York, 334-349.

[7] Baker, P.N. (2012) Operative Interventions in Obstetrics. In: Philips, P.N. and Kenny, L.C., Eds., Obstetrics by Ten Teachers, 19th Edition, Hodder Arnold, London, 24-240.

[8] (2005) Guidelines for Vaginal Birth after Previous Caesarean Birth. SOGC Clinical Guidelines No. 155. http://sogc.org/wp-content/uploads/2013/01/155E-CPG-February2005.pdf

[9] Royal College of Obstetricians and Gynaecogists (2015) Birth after Previous Caesarean Birth. Green-Top Guideline No. 45.

[10] Biswass, A. (2003) Management of Previous Caesarean Section. Current Opinion in Obstetrics \& Gynecology, 15, 123-129. http://dx.doi.org/10.1097/00001703-200304000-00007

[11] Quilligan, E. (2001) Vaginal Birth after Caesarean Section: 270 Degrees. Journal of Obstetrics and Gynaecology Researchs, 27, 169-173. http://dx.doi.org/10.1111/j.1447-0756.2001.tb01247.x

[12] Landon, M.B., Hauth, J.C., Leveno, K.J., Spon, C.Y., Leindecker, S., Varner, M.W., et al. (2004) Maternal and Perinatal Outcomes Associated with a Trial of Labour after Prior Caesarean Delivery. The New England Journal of Medicine, 351, 2581-2589.

[13] Macones, G.A., Pelpert, J., Odibo, A., Stevens, E.J., Stamilio, D.M., et al. (2005) Maternal Complications with Vaginal Birth after Caesarean Delivery: Multicenter Study. American Journal of Obstetrics \& Gynecology, 193, 1656-1662.

[14] Clark, S.L. and Hankins, G.D. (2003) Temporal and Demographic Trends in Cerebral Palsy—Facts and Fiction. American Journal of Obstetrics \& Gynecology, 188, 628-33. http://dx.doi.org/10.1067/mob.2003.204

[15] Obiefuna, N.J.A., Ezeama, C.O., Ezenri, U. and Ugboaja, J.O. (2007) Outcome of Pregnancy Following a Previous Lower Segment Caesarean Section: A Five Year Study at the Nnamdi Azikiwe University Teaching Hospital, Nnewi. Tropical Journal of Medical Research, 11, 25-28.

[16] Sharma, S. and Thope-Beeston, J.G. (2002) Trial of Vaginal Delivery Following Three Previous Caesarean Sections. BJOG, 109, 350-351. http://dx.doi.org/10.1111/j.1471-0528.2002.01037.x 